\title{
Modeling the effect of paying basic income to unemployed citizens of the Russian Federation
}

\author{
V. N. Bobkov ${ }^{1,2, *}$, I. B. Kolmakov ${ }^{2}$, and E. V. Odintsova ${ }^{1}$ \\ ${ }^{1}$ Institute of Socio-Economic Studies of Population, Federal Center of Theoretical and Applied \\ Sociology, Russian Academy of Sciences, 32, Nakhimovsky ave., Moscow, 117218, Russia \\ ${ }^{2}$ Plekhanov Russian University of Economics, 36, Stremyanny lane, Moscow, 117997, Russia
}

\begin{abstract}
The substantiation of the mechanism of payment of temporary basic income for unemployed Russian citizens registered with the state employment service is proposed. The introduction of this mechanism is considered as a possible experiment for testing transitional forms of universal basic income in the Russian Federation. The modeling was carried out using the R1-4 simulation expert model of GDP reproduction of the Russian economy, which is adapted to assess the effect and costs of the proposed hypothetical "Conditional Basic Income (CBI) Program". The functioning of the CBI Program after one-time start-up costs for its launch is ensured in the future by the annual multiplicative increase in the consolidated budget income of the Russian Federation.
\end{abstract}

\section{Introduction}

Universal basic income (UBI) is a social benefit, a regular payment of a fixed amount of money from the state to all citizens of a country, guaranteeing them a minimum level of consumption of goods, services and information, regardless of the type of activity, economic and social status.

Experiments on the introduction of UBI have been discussed, carried out or are planned in a number of countries: India, Spain (Barcelona), Italy, Canada, Kenya, Namibia, Netherlands (Amsterdam, Utrecht), USA (Alaska), Uganda, Finland, Switzerland and others [1]. According to a published report by the United Nations Development Program (UNDP), the immediate introduction of a temporary basic income for the world's poorest people could slow the current surge in COVID-19 cases, allowing nearly three billion people to stay at home [2].

Research problems of the UBI category are identified in published works, for example, $[3,4]$. Based on the concept of the inevitability of the introduction of the UBI system, it is necessary to solve the problems of studying the options for the functioning of such systems. What could be the source of this income, what could be the amount of UBI, the number of consumers, and, consequently, the amount of government spending? For the Russian Federation, there are no answers to these questions yet.

\footnotetext{
${ }^{*}$ Corresponding author: bobkovvn@ mail.ru
} 
The measures taken by the Government of the Russian Federation to support the employment sector during the acute phase of COVID-2019 showed their inadequacy: unemployment benefits were raised to the subsistence level, but not for all unemployed registered with employment services. Even taking into account the additional payments for minor children in families of the unemployed and other payments to households, all of them did not allow them to compensate for the lost income and maintain an acceptable standard of living.

The financial reserves of the Russian Federation make it possible to make the start-up costs for the introduction of an experimental "Conditional Basic Income Program (CBI Program)" aimed at improving the living standards of unemployed citizens.

\section{Data and methods}

Application of the previously developed macroeconomic approaches of long-term forecasting to the implementation of the CBI Program could look as follows. For these purposes, a R1-4 simulation expert model of gross domestic product (GDP) reproduction of the Russian economy [4-7] has been developed and is being successfully operated, which can be used to assess the effect and costs of the CBI Program. All economic characteristics of the model correspond to the reporting of the Russian Federal State Statistics Service (Rosstat).

R1-4 model uses the ratios of the System of National Accounts (SNA) and the fundamental characteristics of the Russian economy as working hypotheses, i.e. stable time dependences of the main macroeconomic indicators. R1-4 model uses modified accounts for the economy as a whole, taken from official accounts.

An additional source of CBI financing is the funds expected from the multiplier effect of the initial target financial costs (TFC), which arises when stimulating consumer demand.

The theoretical substantiation of the multiplier effect of the TFC can be obtained in the models of an idealized economy.

In the account of goods and services, GDP is determined by the sum of gross capital formation GF, final consumption Y, and the balance of foreign trade transactions FT, i.e. as in equation (1). Whence we get equation (2).

$$
\begin{aligned}
& G D P=G F+Y+F T \\
& G F+Y=G D P-F T
\end{aligned}
$$

The amount GF + Y is called the 'generalized supply', which should be equal to the 'generalized effective demand'.

The cost of material flows is assumed to be equal to the financial allocations. Whence equations (3) and (4) follow.

$$
\begin{aligned}
& G F=\operatorname{asg} G F \\
& Y=\operatorname{asg} Y
\end{aligned}
$$

Financial allocations for gross capital formation and final consumption are presented as linear functions of GDP.

$$
\begin{aligned}
& \operatorname{asg} G F=k 1 * G D P+R 1 \\
& \operatorname{asg} Y=k 2 * G D P+R 2
\end{aligned}
$$

In equation (6), k1, R1, k2, R2 are the regression coefficients. 
The sum asgGF + asgY is called 'generalized effective demand'. Formally, the values GDP, GF, Y, asgGF, asgY are unknown variables. Formally, parameters FT, R1, R2, k1, k2 are known constants.

Substituting the expressions for the appropriations into the original equation for GDP, we obtain equation (7), from which we obtain (8).

$$
\begin{gathered}
G D P=k 1 * G D P+k 2 * G D P+R 1+R 2+F T \\
G D P=\frac{R 1+R 2+F T}{1-k 1-k 2}
\end{gathered}
$$

Substituting the found GDP value (equation (8)) into equation (5) and using identity (3), we obtain equation (9).

$$
G F=k 1 * \frac{R 1+R 2+F T}{1-k 1-k 2}+R 1
$$

Similarly, substituting the found GDP value (equation (8)) into equation (6) and using identity (4), we obtain equation (10).

$$
Y=k 2 * \frac{R 1+R 2+F T}{1-k 1-k 2}+R 2
$$

To solve real problems, numerical methods are used for solving systems of nonlinear equations. For this, a certain initial approximation of GDP and a number of other parameters is set in each year of the forecast period, and then a process of successive substitutions is generated, which lasts until the required balances are achieved for a given solution accuracy. Thus, a multidimensional trajectory of future macro indicators is obtained.

To estimate the amount of additional income for CBI payments, a numerical experiment was performed using the R1-4 economic and mathematical model.

\section{Modelling and calculations}

According to the Ministry of Labor of the Russian Federation, up to 5.5-6 million unemployed are expected by the end of 2020 [8]. How much will the it cost to the state for the annual support of so many unemployed? In order to more realistically meet the minimum needs of the unemployed, taking into account the family burden, they need to be paid an allowance in the amount of at least three subsistence minimum of the working-age population (SMw.) This will require 2183.4 billion rubles of annual expenses for supporting registered unemployed.

It was assumed that the program will begin in 2020 and will last until 2025, which formally means the addition of 2.2 trillion rubles to the current value of household final consumption expenditure (HFCE) in the first year in this period of time. The initial amount is supposed to be taken from the National Welfare Fund. After the first year, the CBI Program will "operate at full capacity", i.e. in the interval 2021 - 2025, goods and services will be sold for an amount that annually exceeds the initial costs approximately two times.

Experimentally, two trajectories of indicators of the development of the economy of the Russian Federation in the interval 2020 - 2025 were constructed - the trajectory of inertial development and the so-called 'indigenous' trajectory, where the household final consumption increases by 2.2 trillion rubles. Comparison of these trajectories determines the contribution of CBI fundraising measures to the Russian economy. The projected trajectories of household final consumption expenditure (HFCE) are shown in Figure 1. 


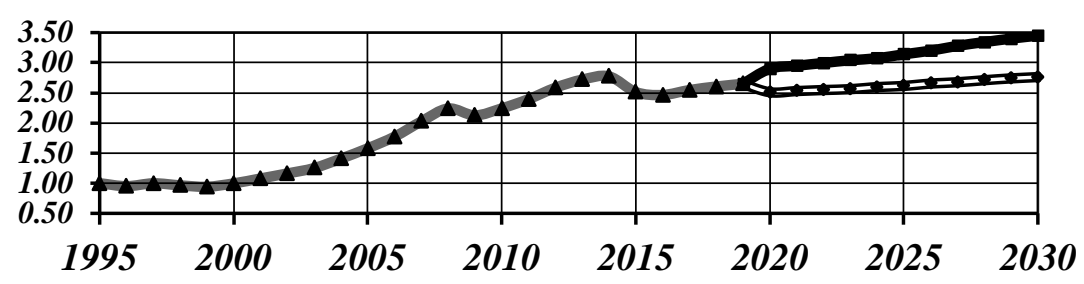

Fig. 1. The dynamics of the basic rates of household final consumption expenditure with inertial and 'indigenous' economic development (during the implementation of the CBI Program).

Line on the segment 1995 - 2019 (Figure 1) characterizes the reported behavior of the baseline efficiency rates of HFCE. The bottom line in the segment 2020 - 2030 characterizes the predicted behavior of the baseline efficiency rates of HFCE with the inertial economic development. The upper line in the segment 2020 - 2030 characterizes the predicted behavior of the baseline efficiency rates of HFCE in the case of 'indigenous' economic development.

Increases in the income of the consolidated budget of the Russian Federation relative to the values of the trajectory of inertial development in 2021-2025 are shown in Table 1.

Table 1. Increases in the income of the consolidated budget (CB) of the Russian Federation.

\begin{tabular}{|c|c|c|c|c|c|}
\hline Years & 2021 & 2022 & 2023 & 2024 & 2025 \\
\hline $\begin{array}{c}\text { Increase in the CB income } \\
\text { (trillion rubles) }\end{array}$ & 4.747 & 5.269 & 5.424 & 5.487 & 5.531 \\
\hline
\end{tabular}

Additional incomes of the consolidated budget of the Russian Federation fully compensate for the initial expenses. The functioning of the CBI Program in the considered variant, after one-time start-up costs for launching the program, is ensured in the future by an annual increase in the consolidated budget income.

\section{Conclusion}

A quantitative assessment of the multiplier effect of initial investments in increasing the effective demand of unemployed citizens of the Russian Federation through experiments on the R1-4 model is obtained. The simulation results show the effect of the implementation of the CBI Program for unemployed citizens of the Russian Federation, which consists in a significant increase in the size of social benefits in the form of CBI with an expanded reproduction of the increment in the income of the consolidated budget of the Russian Federation.

\section{Acknowledgments}

The reported study was funded by the Russian Foundation for Basic Research (RFBR), project number 20-010-00271.

\section{References}

1. Chernykh E A 2020 J. Liv. Stand. Popul. Reg. of Russia 2 61-75

2. Gray Molina G and Ortiz-Juarez E 2020 Temporary basic income: Protecting Poor and Vulnerable People in Developing Countries (New York: UNDP) p 24

3. Bobkov V N, Dolgushin N T and Odintsova E V 2019 J. Liv. Stand. Popul. Reg. of Russia 38 
4. Kolmakov I B and Antipov V I 2016 Bulletin PRUE 2(86) 130

5. Antipov V I 2020 Stagnation of the Russian economy and the Food cards program Russia:Trends and prospects of development Yearbook (Moscow: INION RAN) p 17

6. Antipov V I, Mitin N I and Pashchenko F F 2018 Keldysh Institute Preprints 272 (Moscow: KIAM) p 36

7. Antipov V I and Kolmakov I B Program for calculating the multiplier of target household expenditures. Certif. registr. computer program RU 2016616984, 22.06.2016. Appl. No 2016614237 dated 22.04.2016

8. Gimpelson V 2020 Coronacrisis 2020: what will happen and what will be done? Development scenarios and economic policy measures (Moscow: Liberal mission) p 24 